\title{
Partial Invasive Mole with Bilateral Torsion of Theca Lutein Cysts
}

\author{
Randhir Sagar Yadav, ${ }^{1}$ Shumneva Shrestha, ${ }^{1}$ Santosh Sharma, ${ }^{1}$ Meeta Singh, ${ }^{2}$ Kesang Diki Bista, ${ }^{2}$ Neebha Ojha ${ }^{2}$ \\ ${ }^{1}$ Maharajgunj Medical Campus, Institute of Medicine, Maharajgunj, Kathmandu, Nepal, ${ }^{2}$ Department of \\ Obstetrics and Gynecology, Tribhuvan University Teaching Hospital, Maharajgunj, Kathmandu, Nepal.
}

\begin{abstract}
Gestational trophoblastic neoplasia is extremely rare entity accounting $1 \%$ of all gynecological malignancies. Invasive mole is a form of Gestational trophoblastic neoplasia which is locally invasive with propensity of metastasis. Association of partial mole with invasive mole and/or theca lutein cysts is a rare occurrence. Large cysts may present with complications. A case with these rare combinations presented at $15^{+3}$ weeks period of gestation as acute abdomen due to torsion of bilateral theca lutein cysts is reported. Right salpingo-ophorectomy with untwisting of left cyst was done. Six cycles of chemotherapy was given with regular $\beta$ hCG monitoring. First trimester dating scan would have helped in early diagnosis, treatment and prevention of complications.
\end{abstract}

Keywords: Invasive mole; theca lutein cysts; torsion.

\section{INTRODUCTION}

Gestational trophoblastic disease (GTD) denotes a spectrum of pregnancy related tumors arising from abnormal placental trophoblast cells. These are broadly classified as molar (partial and complete) and nonmolar tumors or Gestational trophoblastic neoplasia (GTN). Invasive mole is locally invasive tumor characterized by edematous chorionic villi with trophoblastic proliferation. It mostly arise from complete mole ${ }^{1}$ or rarely from partial mole. ${ }^{2,3}$ Theca lutein cysts (TLCs) rarely occur with partial mole. The possibility of GTN is an important consideration while diagnosing GTD. GTN is a very rare neoplasm accounting less than $1 \%$ of entire gynecological malignancies. An unusual case with such rare combinations presenting at Tribhuvan University Teaching Hospital is reported here.

\section{CASE REPORT}

A 21 year old, primigravida with normal first antenatal checkup at 11 weeks period of gestation (POG) presented at $15^{+3}$ weeks POG with acute onset of severe lower abdominal pain for five hours associated with four episodes of vomiting. She denied history of bleeding per vaginum $(P V)$, syncopal attack or fever. She looked ill but vital parameters were stable. Abdomen was soft with palpable uterus corresponding to 22 weeks size. Tenderness and rebound tenderness were present over right iliac fossa. Per speculum examination showed no abnormality. Bimanual examination revealed 22 weeks size uterus with full and tender bilateral fornices. Urgent ultrasonography revealed molar pregnancy with approximately $6.9 \times 5.3 \mathrm{~cm}$ and $9.6 \times 7.8 \mathrm{~cm}$ TLCs within left and right adnexa respectively. Routine investigations were within normal limits except hemoglobin of 10 $\mathrm{gm} \%$ and serum BhCG level was 12,50,400 $\mathrm{mlU} / \mathrm{ml}$. An attempt of transabdominal ultrasonography guided aspiration of distended bilateral TLCs at bilateral iliac fossa was unsuccessful. Patient was admitted, suction and evacuation (S\&E) was done and the cavity was evacuated of about 600 gms of blood mixed tissues with multiple clear vesicles. Following S\&E her condition improved. Re-emergence of pain on following day necessitated emergency laparotomy. Per-operatively, about $300 \mathrm{ml}$ of serosanguinous fluid was present in the peritoneal cavity. Uterus was soft corresponding to 14 weeks size. Bilateral ovarian masses as mentioned in figure 1 were observed. Right salpingo-ophorectomy (RSO) with untwisting of left TLC with aspiration was done. Three days after S\&E serum BhCG was 53613 mIU/ $\mathrm{ml}$. On fifth post-operative day (POD), as there was PV bleeding, pelvic ultrasonography was done which showed features of retained product of conception (POC). MRI planned to rule out invasive mole showed findings of invasive mole (figure $2 \mathrm{~A}$ ) with multiple TLC in left ovary (figure 2B). Correlative ultrasonography showed lesion confined to myometrium with intact
DOI: http://dx.doi.org/10.3126/ jnhrc.v15i3.18861
Correspondence: Randhir Sagar Yadav, Maharajgunj Medical Campus, Institute of Medicine, Maharajgunj, Kathmandu, Nepal. Email: sagar.randhir@gmail.com, Phone: : +9779851214120 . 
Partial Invasive Mole with Bilateral Torsion of Theca Iutein Cysts

serosal layer with no parametrial tissue invasion (figure 2C). Colour doppler showed irregular intense vascularity within (figure 2D). Patient was discharged on sixth POD on oral antibiotics, analgesics and hematinics.

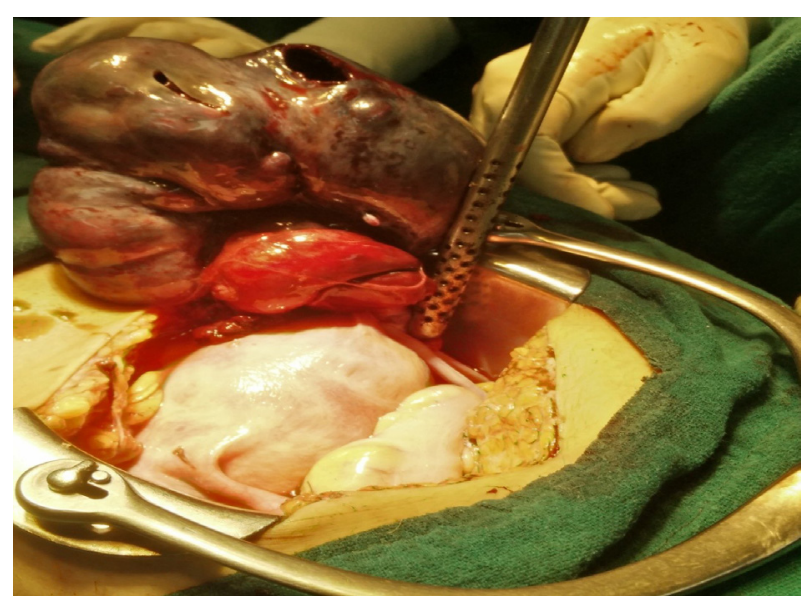

Figure 1. Mass arising from right ovary: Approximately $11 \times 11 \mathrm{~cm}$ mass twisted three times on its pedicle with dark bluish discoloration, multilobulated smooth surface with two rents on its surface each measuring approximately $1.5 \mathrm{~cm}$ with active oozing. Mass arising from left ovary: Approximately $10 \times 9 \mathrm{~cm}$ mass which was partially twisted on its pedicle with multilobulated smooth surface.

A

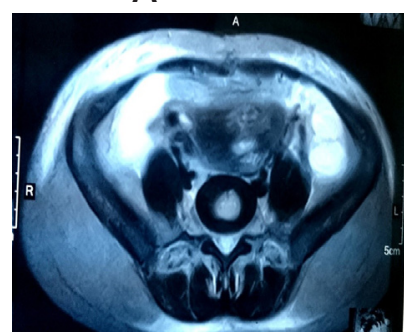

B
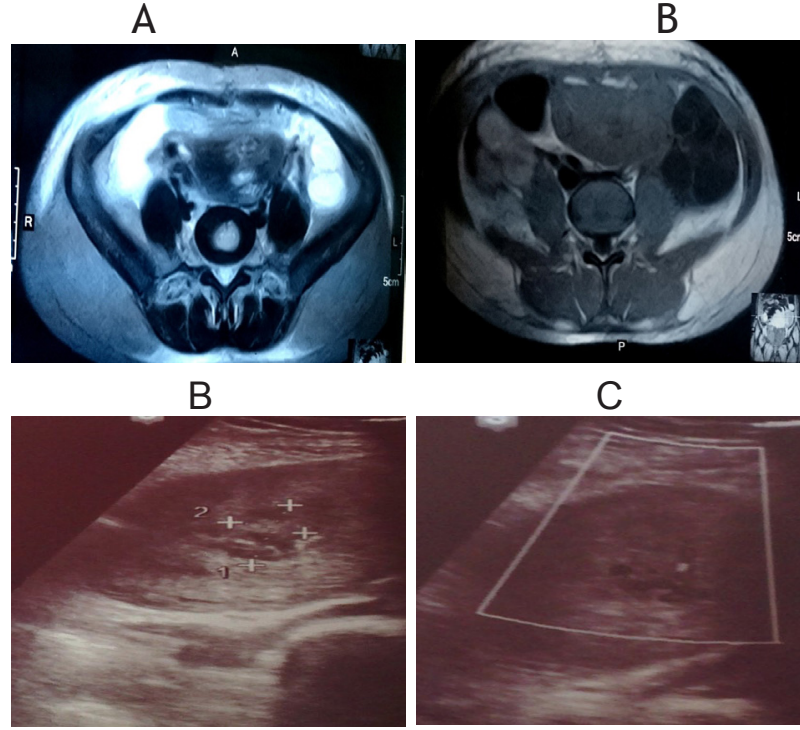

C

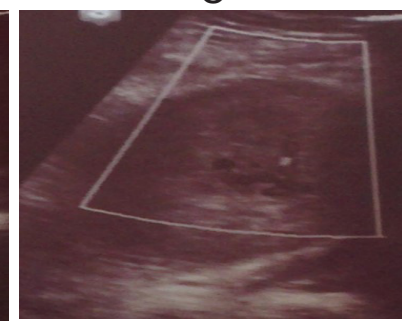

Figure 2A. Heterogenous T2 and STIR high signal intensity ill-defined lesion noted in the posterior wall of fundus of uterus, extending in to the myometrium with no extension into the parametrial tissue. 2B. Multiple theca lutein cyst in left ovary. 2C. Bulky uterus with heteroechoic area approximately $2.9 \times 1.7$ $\mathrm{cm}$ noted within uterine cavity with intact serosal layer with no parametrial tissue invasion. 2D. Increased vascularity of myometrium in left fundic region.
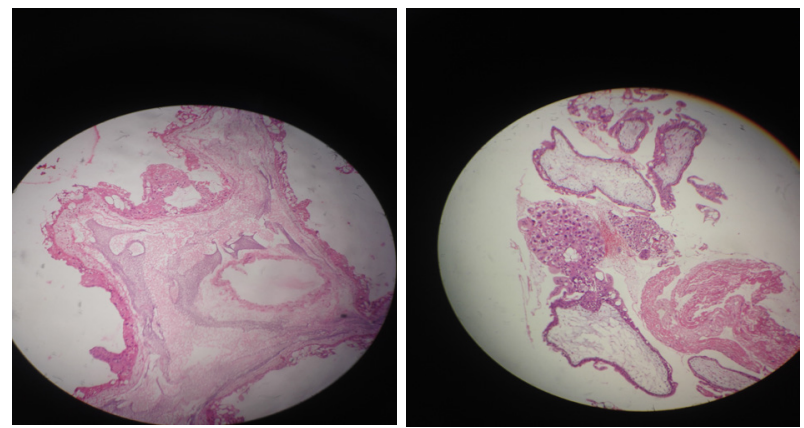

Figure 3. Section showing normal and dilated villi with hydropic degeneration and focal trophoblastic proliferation suggestive of partial hydatiform mole.

During routine follow up on $12^{\text {th }}$ POD she complained of continued PV bleeding. Histopathology examination (HPE) of molar tissue revealed partial $\mathrm{H}$. mole while HPE of twisted ovary showed hemorrhagic infract (figure 3 ). On repeat S\&E about 10 gm retained POC was removed. Weekly serum BhCG surveillance was in decreasing trend ( $53613 \mathrm{mlU} / \mathrm{ml}$ to $6407 \mathrm{mlU} / \mathrm{ml}$ prior to chemotherapy and $1817 \mathrm{mlU} / \mathrm{ml}$ and $976 \mathrm{mlU} / \mathrm{ml}$ in the successive weeks following chemotherapy). With the impression of GTN (invasive mole) FIGO stage I and WHO prognostic score 5 (low risk), patient was managed with single agent chemotherapy on OPD basis. Methotrexate (MTX: $50 \mathrm{mg} ; 1 \mathrm{mg} / \mathrm{kg}$ intramuscular (IM) on days $1,3,5$, and 7) with Folinic acid (FA: $5 \mathrm{mg} ; 0.1 \mathrm{mg} / \mathrm{kg} I \mathrm{M}$ on days 2, 4, 6 , and 8 ) rescue regimen was given. Chemotherapy was started two weeks post S\&E when BhCG was 6407 mlU/ $\mathrm{ml}$. She received six cycles of chemotherapy on weekly basis until her BhCG normalized $(3 \mathrm{mlU} / \mathrm{ml})$ after eight weeks of S\&E. She is on regular follow up with monthly BhCG monitoring.

\section{DISCUSSION}

Clinically, the diagnosis of partial mole is often missed and thus needs histological confirmation. ${ }^{3}$ Development of partial mole into invasive form is extremely rare. ${ }^{2}$ Similarly, about $0.5 \%$ of partial and $10-15 \%$ of complete moles are reported to develop into GTN. ${ }^{3}$ Invasive mole is aggressive in nature with varying propensity of myometrial invasion and metastasis. Patients with invasive mole present with persistent PV bleeding following evacuation as in this case. Ultrasonography and uterine curettage are inconclusive in absence of adequate myometrium invasion. HPE verifies invasion. MRI is the definitive diagnostic modality to establish myometrial invasion in equivocal or complicated cases. ${ }^{4}$ MRI confirmed invasion in our case. Raised serum BhCG, HPE, colour doppler imaging and MRI established diagnosis in our patient. S\&E is the preferred method where fertility preservation is desired. ${ }^{5}$ Maintaining 
fertility of our young primi was essential. Post molar malignant sequel in partial mole is significantly low, by figure $3-5 \%{ }^{6}$ Following evacuation, $1.2 \%$ to $4 \%$ partial mole develop persistent disease while only $0.1 \%$ metastasize. $^{7}$ However, $10-28 \%$ complete mole show persistent disease or malignant complication. ${ }^{5}$ Finding of TLCs with partial mole is rare whereas $25 \%$ to $60 \%$ complete mole express association.

TLCs accounts $25 \%$ of molar pregnancies. ${ }^{8}$ It may resolve spontaneously over several months. Complications like rupture and torsion of cysts are rare. Larger cysts have chances of torsion, infarction and hemorrhage. Surgical interventions are reported in $3 \%$ of cysts. ${ }^{8}$ Oophorectomy is not recommended unless ovary is extensively infarcted. In our patient, both cysts were large with torsion. Right ovary and fallopian tube was infarcted requiring RSO. Diagnostic laparoscopy or overiopexy could be alternative interventions. About $75 \%$ of bilateral TLCs have a post molar squeal. ${ }^{8}$ Post molar sequel leading to increasing BHCG levels is responsible for secondary enlargement in approximately $30 \%$ of $\mathrm{TLCs}^{8}{ }^{8}$ The risk of developing persistent GTD goes higher if anyone among pre-evacuation BhCG level $>10^{5} \mathrm{mlU} / \mathrm{ml}$, TLCs $>6 \mathrm{~cm}$ in diameter or large uterine size is supportive. ${ }^{9}$ BhCG in this case regressed markedly despite there were risk factors for persistent GTD. Appropriate management on time cures most GTD. Single agent chemotherapy is recommended in non-metastatic or low risk cases. ${ }^{10}$ Being a non-metastatic and low risk case chemotherapy (MTX+FA regimen) was prudently started early with regular BhCG monitoring in our case. She responded well to the treatment. Despite the rarity of occurrence, large TLCs, high BhCG and large uterine size can be associated partial mole with latter's progression to invasive form necessitating chemotherapy. A case with such combination of rare ailments is exceptional and has not been reported as per authors' information.

\section{CONCLUSIONS}

In our case, a dating scan done in first trimester would have helped to diagnose the molar pregnancy with TLCs earlier and thus reduce the sequel. Furthermore, close follow up for timely detection of sinister pathology to have a healthy reproductive life is an integral part of treatment.

\section{REFERENCES}

1. Sebire NJ, Foskett M, Fisher RA, Lindsay I, Seckl MJ. Persistent gestational trophoblastic disease is rare, if ever, derived from non-molar first-trimester miscarriage. Med Hypotheses. 2005;64(4):689-93. [PubMed]

2. Mandal D, Nandi N, Dey RP, Biswas RR, Bhattacharya AK, Biswas SC. Partial invasive molar pregnancy: Two case reports. Al Ameen J Med Sci. 2010;3(1):91-93. [Full Text]

3. Soper JT, Mutch DG, Schink JC. American College of Obstetricians and Gynecologists. Diagnosis and treatment of gestational trophoblastic disease: ACOG Practice Bulletin No.53. Gynecol Oncol. 2004;93(3):575-85. [PubMed]

4. Kohorn, E.I. Evaluation of the criteria used to make the diagnosis of non-metastatic gestational trophoblastic neoplasia. Gynecol Oncol. 1993;48(2):139-47. [FullText]

5. Berkowitz RS, Goldstein DP. Chorionic tumors. N Engl J Med. 1996;335:1740-48. [Full Text]

6. Hancock BW, Nazir K, Everard JE. Persistent gestational trophoblastic neoplasia after partial hydatidiform mole incidence and outcome. J Reprod Med. 2006;51:764-66. [Full Text]

7. Hancock BW, Tidy JA. Current management of molar pregnancy. J Reprod Med. 2002;47(5):347-54. [Full Text]

8. Montz FJ, Schlaerth JB, Morrow CP. The natural history of theca lutein cysts. Obstet Gynecol. 1988;72(2):247-51. [Full Text]

9. Goldstein DP, Berkowitz RS, Bernstein MR. Management of molar pregnancy. J Reprod Med. 1981;26(4):208-12. [PubMed]

10. Horowitz NS, Goldstein DP, Berkowitz RS. Management of gestational trophoblastic neoplasia. Semin Oncol. 2009;36(2):181-89. [PubMed] 